\title{
Combination of HDE and BIIB021 efficiently inhibits cell proliferation and induces apoptosis via downregulating hTERT in myelodysplastic syndromes
}

\author{
BO WANG ${ }^{1}$, JIANPING JIANG ${ }^{2}$, YUN ZHANG ${ }^{1}$, YINGYING SHEN ${ }^{1}$, \\ LIQIANG WU ${ }^{1}$, SIQI TANG ${ }^{3}$ and SHENGYUN LIN ${ }^{1}$ \\ ${ }^{1}$ Department of Hematology, ${ }^{2}$ Preparation Center, The First Affiliated Hospital of Zhejiang Chinese Medical University, \\ Hangzhou, Zhejiang 310006; ${ }^{3}$ Laboratory of Molecular Neuropharmacology, School of Pharmacy, \\ East China University of Science and Technology, Shanghai 200237, P.R. China
}

Received November 14, 2019; Accepted September 24, 2020

DOI: $10.3892 /$ etm.2021.9934

\begin{abstract}
Treatment for higher-risk patients with myelodysplastic syndrome (MDS) should aim to modify the disease course by avoiding progression to acute myeloid leukemia and improving survival. When a patient is not eligible for intensive chemotherapy and lacks a donor hematopoietic cell source, or for a patient in a poor economic situation, consideration can be given to the use of Chinese herbal medicine. Numerous plant extracts, such as camptothecin, vinblastine and paclitaxel, have been reported to display antitumor effects, serving as potential therapeutic strategies for cancer. In the present study, the ultra-performance liquid chromatography-tandem mass spectrometry system (Waters Corporation) was used to detect the main chemical components of HDE, CCK-8 assay to detect the effects of HDE and BIIB021 on the proliferation of SKM-1 cells; and designed hTERT-small interfering (si) RNAs to detect the effects of HDE and BIIB021 on SKM-1 cell apoptosis after HTERT gene knockdown. The present study investigated a newly extracted coumarin HDE, the active component in Oldenlandia diffusa Willd, which efficiently inhibited SKM-1 (MDS cell line) proliferation and induced apoptosis, as determined by performing Cell Counting Kit-8 and flow cytometry assays, respectively. The effect of HDE was associated with decreased telomerase activity. Moreover, heat shock protein 90 inhibitor BIIB021 significantly enhanced the antitumor effects of HDE on SKM-1 cells. In addition, SKM-1 cell apoptosis was increased in human telomerase reverse
\end{abstract}

Correspondence to: Dr Shengyun Lin, Department of Hematology, The First Affiliated Hospital of Zhejiang Chinese Medical University, 54 Youdian Road, Hangzhou, Zhejiang 310006, P.R. China

E-mail: 1syww2012@163.com

Key words: myelodysplastic syndrome, antitumor effects, human telomerase reverse transcriptase, drug combination transcriptase (hTERT)-knockdown cells compared with the negative control group. Cell apoptosis in hTERT-knockdown SKM-1 cells was further enhanced following HDE, BIIB021 or combination treatment, as evidenced by increased levels of cleaved caspase 3 , cleaved caspase 8 and cleaved poly ADP ribose polymerase. Collectively, the results indicated synergistic antitumor effects of HDE and BIIB021, providing a novel therapeutic combination for higher-risk MDS.

\section{Introduction}

Myelodysplastic syndromes (MDSs) are incurable malignant hematological diseases caused by malfunctioning hematopoietic stem cells (HSC) or CD34+ progenitor cells (1). A substantial proportion of MDSs arise in the setting of exposure to environmental or occupational toxins, including cytotoxic therapy for a prior malignancy or other disorder (2). Patients with MDS are classified as lower-risk or higher-risk according to different prognostic scoring systems $(3,4)$. The incidence of MDS progression to acute leukemia is 3.3/100,000 (5). According to the revised International Prognostic Scoring System (2012), high-risk and extremely high-risk patients often display multiple morbid hematopoiesis and malignant clonal hyperplasia, which can easily transform into leukemia, leading to a median survival of 1.6 and 0.8 years, respectively (6). Due to its poor prognosis, the treatment of higher-risk MDS has received increasing attention. Stem cell transplantation remains the most effective treatment strategy for patients with higher-risk MDS, but only a few patients are eligible for this treatment strategy $(3,7)$. The primary chemotherapy regimen for patients with higher-risk MDS is hypomethylating agents (HMAs) (8); however, as only $\sim 50 \%$ of patients with higher-risk MDS respond to HMA treatment and the response is often transient, there is a need to improve the treatment strategy for higher-risk MDS.

On the genomic level, MDS is classified by losses and translocations involving certain key gene segments, with disruption of the normal structure and function of genes that control the balance of proliferation and differentiation of hematopoietic precursors (9). The evidence suggests that unidentified tumor 
suppressor genes may serve important roles in the molecular mechanisms underlying MDS $(10,11)$. Further molecular approaches to genetic lesions will aid with the identification of relevant tumor suppressor genes. Over the past few years, major signal transduction molecules, their genetic alteration molecules, cell cycle regulators, and transcription factors have been identified (9). In particular, transcription factors such as EVI-1, that regulate both hematopoietic stem cell proliferation and differentiation were identified (12). Disruption of signal transduction pathways involving these molecules results in ineffective multilineage hematopoiesis and bone marrow failure (13).

Activation of telomerase can lead to uncontrollable cell proliferation or even tumorigenesis, and $\sim 90 \%$ of malignant and immortalized cells display abnormal telomerase activity (14). In contrast to normal cells, heat shock protein 90 (HSP90) is continuously activated in cancer cells (15) and highly expressed in hematological malignancies, especially in acute leukemia (16). HSP90 and the co-chaperone p23 bind to human telomerase reverse transcriptase (hTERT) to activate telomerase during tumorigenesis $(17,18)$. HSP90 expression is higher in patients with higher-risk MDS compared with patients with lower-risk MDS, and is therefore positively correlated with the risk of MDS conversion to acute leukemia and poor prognosis $(19,20)$. It was hypothesized that high HSP90 expression contributes to higher-risk MDS-induced leukemia via reactivation of hTERT; hence, inhibiting HSP90 activity and promoting substrate degradation with specific inhibitors should inhibit MDS cell proliferation and conversion. BIIB021, a derivative of the first sputum compound PU3, is a new generation terpenoid that is currently in clinical trials for the treatment of solid tumors and hematological malignancies $(21,22)$. Therapeutically, higher-risk MDS is insensitive to common chemotherapy, and bone marrow transplantation is often hindered by human leukocyte antigen (HLA) mismatch, high costs, immune rejection and postoperative infections (23). Moreover, the use of demethylation drugs, such as 5-aza cytidine and 5-aza-2 deoxycytidine, is typically limited due to non-specific toxicity, potential carcinogenicity and drug resistance (24). Therefore, novel treatment strategies for higher-risk MDS with higher efficacy, reduced aggression, fewer side effects and lower cost are urgently needed.

Based on the difficulties and risks of higher-risk MDS in clinical treatment, the present study aimed to investigate the pathogenesis of the disease and combine the advantages of traditional Chinese medicine (for example, low toxicity and side effects) to evaluate its advantages for the treatment of higher-risk MDS. Oldenlandia diffusa Willd belongs to the hedyotis genus of rubiaceous family, which grows in the south of the Yangtze River in China (23). Oldenlandia diffusa Willd is a widely used Chinese herbal medicine that has been reported to display the following effects: lowering heat, detoxification, promoting blood circulation, clearing blood stasis and benefiting diuresis (23). Higher-risk and extreme higher-risk MDS are diagnosed as visceral dysfunction and Shengqi deficiency by the traditional Chinese medicine system (25). Oldenlandia diffusa Willd is a herbal prescription for the treatment of visceral dysfunction, and previous studies have indicated that that Oldenlandia diffusa Willd displays anti-inflammatory, antibacterial, immune-enhancing and antitumour effects (26-28).
It has been previously reported that the total coumarins of Hedyotis diffusa (TCHD) could inhibit SKM-1 cell (MDS cell line) proliferation (23). The present study aimed to preliminarily explore the potential use of HDE extracted from Oldenlandia diffusa Willd combined with HSP90 inhibitor BIIB021 for the treatment of MDS in vitro.

\section{Materials and methods}

Plant material and reagents. Authentic plant material of HDE was purchased from Zhejiang University of Traditional Chinese Medicine Chinese Medicine Decoction Pieces Co., Ltd. and identified by Dr Jianping Jiang at Zhejiang Chinese Medical University (voucher specimen: Jiang J.P., 141001, ZM). The dried and sliced HDE material was ground into fine powder before extraction.FBS and RPMI-1640 medium were purchased from Gibco (Thermo Fisher Scientific, Inc.). BIIB021 was purchased from Selleck Chemicals (cat. no. S1175). All other reagents were obtained from Sigma-Aldrich (Merck KGaA).

Cell culture and preparation. The SKM-1 cell line was purchased from The Cell Bank of Type Culture Collection of the Chinese Academy of Sciences. Cells were cultured with RPMI-1640 (Gibco; Thermo Fisher Scientific, Inc.) supplied with $10 \%$ (v/v) FBS (Gibco; Thermo Fisher Scientific, Inc.) and penicillin-streptomycin under a humidified atmosphere of $5 \% \mathrm{CO}_{2}$ at $37^{\circ} \mathrm{C}$ and used at the logarithmic growth phase. Cells were digested and a cell suspension $\left(8 \times 10^{4}\right.$ cells $\left./ \mathrm{ml}\right)$ was prepared. Subsequently, $100 \mu \mathrm{l}$ cell suspension was added to each well of a 96-well culture plate. Following culture for $24 \mathrm{~h}$ at $37^{\circ} \mathrm{C}$ with $5 \% \mathrm{CO}_{2}$, the drugs were diluted to $0,25,50$, $100,200 \mu \mathrm{g} / \mathrm{ml}$ concentrations and added to the SKM-1 cells with $100 \mu \mathrm{l}$ per well. Following $48 \mathrm{~h}$ incubation for test, bone marrow-derived stem cells (BMSCs; cat. no. HUXMA-90011; Cyagen Biosciences, Inc.) were cultured in $\alpha$-MEM supplemented with 10\% FBS (Gibco; Thermo Fisher Scientific, Inc.) and $100 \mathrm{U} / \mathrm{ml}$ penicillin-streptomycin (Hyclone; GE Healthcare Life Sciences) at $37^{\circ} \mathrm{C}$ with $5 \% \mathrm{CO}_{2}$ in a humidified atmosphere.

Cytotoxicity assay. The drugs were diluted to the required working concentrations in culture medium and $100 \mu \mathrm{l}$ medium was added to each well. A negative control (NC) group (standard curve reference) and experiment control group were simultaneously set up. Cell cytotoxicity was assessed using the Cell Counting Kit-8 (CCK-8) assay (cat. no. 35003; Biosharp Life Sciences) according to the manufacturer's protocol. Following incubation for $48 \mathrm{~h}, 10 \mu \mathrm{l}$ CCK-8 solution was added to each well and incubated for $2-3 \mathrm{~h}$ at $37^{\circ} \mathrm{C}$. The optical density (OD) was measured at a wavelength of $450 \mathrm{~nm}$ using a microplate reader (BioTek Instruments, Inc.; EL-x800). Cell proliferation was calculated according to the following formula: proliferation $(\%)=\left(\mathrm{A}_{\text {drug }}-\mathrm{A}_{\text {blank }}\right) /\left(\mathrm{A}_{0}-\mathrm{A}_{\text {blank }}\right) \times 100$, where $\mathrm{A}_{\text {drug }}$ represents the $\mathrm{OD}$ value of wells containing treated cells, $\mathrm{A}_{\text {blank }}$ represents the OD value of blank wells (no cells) and $\mathrm{A}_{0}$ represents the $\mathrm{OD}$ value of wells containing untreated cells.

Small interfering (si)RNA transfection. siRNA sequences targeting hTERT were designed as follows: hTERT-siRNA-1728 sense, 5'-GGAAGAGUGUCUGGAGCAAGU-3' and antisense, 
5'-UUGCUCCAGACACUCUUCCGG-3'; hTERT-siRNA-966 sense, 5'-CGGUGUACGCCGAGACCAAGC-3' and antisense, 5'-UUGGUCUCGGCGUACACCGGG-3'; and hTERT-siRNA -1464 sense, 5'-GGAACACCAAGAAGUUCAUCU-3' and antisense, 5'-AUGAACUUCUUGGUGUUCCUG-3'); control siRNA (NC) sense, 5'-UUCUCCGAACGUGUCACGUTT-3' and antisense 5'-ACGUGACACGUUCGGAGAATT-3'. SKM- 1 cells $\left(8 \times 10^{4}\right.$ cells/well) were cultured in 24 -well plates for at least $12 \mathrm{~h}$. A total of $100 \mathrm{nM}$ of each siRNA was transfected into SKM-1cells using Lipofectamine $2000^{\mathrm{TM}}$ (Invitrogen; Thermo Fisher Scientific, Inc.) for up to $48 \mathrm{~h}$.

Real-time quantitative PCR analysis. Total RNA was extracted from cells using the EasyPure ${ }^{\circledR}$ Blood RNA kit (TransGen BioTech Co., Ltd.) according to the manufacturer's instructions. Total RNA was reverse transcribed to cDNA using the One Step Goscript Reverse Transcription System kit (Promega Corporation). The reaction mixture contained: $15 \mu 1$ RNA, $1.2 \mu 1$ random primer and $1.2 \mu 1$ Oligo (dT). Following mixing and centrifugation at $1200 \mathrm{x}$ g for $15 \mathrm{sec}$ at room temperature, cDNA was preheated at $70^{\circ} \mathrm{C}$ for $5 \mathrm{~min}$, placed on ice for at least $5 \mathrm{~min}$ and centrifuged at $1200 \mathrm{xg}$ for at least $10 \mathrm{sec}$ at room temperature. The second strand cDNA synthesis mixture contained: $6 \mu 15 \mathrm{X}$ reaction buffer, $3.8 \mu 1 \mathrm{MgCl}_{2}(25 \mathrm{mM})$, $1.5 \mu 1$ PCR nucleotide mix, $0.3 \mu 1$ RNA enzyme inhibitor and $1 \mu 1$ reverse transcriptase. The following thermocycling conditions were used: $25^{\circ} \mathrm{C}$ for $5 \mathrm{~min}, 42^{\circ} \mathrm{C}$ for $1 \mathrm{~h}$ and $70^{\circ} \mathrm{C}$ for $15 \mathrm{~min}$. The cDNA products $(5 \mu \mathrm{l})$ were subjected to electrophoresis using $1 \%$ agarose gel (containing SYBR Green nucleic acid dye). cDNA bands were visualized using a gel imaging system (Tanon Science and Technology Co., Ltd.). The bands were quantified using Quantity One image analysis software (Bio-Rad Laboratories, Inc.) with ACTB as the internal reference gene.

Subsequently, cDNA was diluted using RNase-free water up to $100 \mu \mathrm{l}$ on ice. qPCR was performed using the following reaction mixture (20 $\mu \mathrm{l}): 5 \mu \mathrm{l} \mathrm{cDNA}, 1 \mu \mathrm{l}$ primer $(4 \mathrm{pmol} / \mu \mathrm{l})$, $1 \mu 1$ TaqMan Probe (6 pmol/ $\mu 1$; Genscript), $10 \mu 12 \mathrm{X}$ Mix (Vazyme Biotech Co., Ltd.) and RNase-free water. The following thermocycling conditions were used for qPCR: $37^{\circ} \mathrm{C}$ for $2 \mathrm{~min}, 95^{\circ} \mathrm{C}$ for $5 \mathrm{~min}$, and denaturation at $95^{\circ} \mathrm{C}$ for $10 \mathrm{sec}$ and $60^{\circ} \mathrm{C}$ for $30 \mathrm{sec}$, followed by 40 amplification cycles. The relative expression levels were analyzed according to the $2^{-\Delta \Delta C T}$ method (29). The sequences of primers and probes (NCBI Bank) were as follows: hTERT forward, 5'-GTGGTT TCTGTGTGGTGTCA-3' and reverse, 5'-GGAGTAGAGGAA GTGCTTGG-3'; actin- $\beta$ (ACTB) forward, 5'-GATGAGATTG GCATGGCTTT-3' and reverse, 5'-GTCACCTTCACCGTT CCAGT-3'; HSP90 forward, 5'-CAGTTGGAATTCAGAGC CCTTCT-3' and reverse, 5'-TCACGGGATATGTTTAGAGG GAG-3'; TaqMan probe, 5'-6-FAM-TTTGTCCCACGACG TGCTCCTTTTG-BHQ1-3'; GAPDH forward, 5'-CTGACT TCAACAGCGACACC-3' and reverse, 5'-GTGGTCCAGGG GTCTTACTC-3'; and TaqMan probe, 5'-6-FAM-CATTGCC CTCAACGACCACTTTGTCA-BHQ1-3'.

Telomerase activity detection by TRAP-ELISA. SKM-1 cell telomerase activity was assessed using the TEELISA kit (cat. no. CSB-E08021h; Cusabio Technology LLC, USA) according to the manufacturer's instructions. Following treatment for $24 \mathrm{~h}$, cells $\left(1 \times 10^{6}\right)$ were centrifuged at $4200 \mathrm{x} \mathrm{g}$ for $20 \mathrm{~min}$ at $4^{\circ} \mathrm{C}$. The cell pellet was incubated with cold lysis buffer $(200 \mu \mathrm{l})$ form the aforementioned kit, for $30 \mathrm{~min}$ on ice. The supernatant $(2 \mu 1)$ was used as the TRAP reaction template. Subsequently, $25 \mu 1$ reaction mixture was added to the PCR reaction tube and the total volume was adjusted to $50 \mu \mathrm{l}$ with DEPC-treated sterilized double distilled water to perform the TRAP reaction according to the following protocol: primer extension for $10 \mathrm{~min}$ at $25^{\circ} \mathrm{C}$; telomerase inactivation for $5 \mathrm{~min}$ at $94^{\circ} \mathrm{C} ; 30$ cycles of denaturation for $30 \mathrm{sec}$ at $94^{\circ} \mathrm{C}$, annealing for $30 \mathrm{sec}$ at $50^{\circ} \mathrm{C}$ and extension for $90 \mathrm{sec}$ at $72^{\circ} \mathrm{C}$; and extension for $10 \mathrm{~min}$ at $72^{\circ} \mathrm{C}$. The amplified product $(5 \mu \mathrm{l})$ and the denaturant $(20 \mu \mathrm{l})$ were mixed and maintained at room temperature for $10 \mathrm{~min}$. Subsequently, $225 \mu 1$ hybridization solution (containing digoxin-labeled probe) was added, and after mixing, $100 \mu 1$ mixture was added to an anti-biotin coated plate and incubated for $2 \mathrm{~h}$ at $37^{\circ} \mathrm{C}$ (300 rpm). Then peroxidase was added and developed with TMB substrate for $30 \mathrm{~min}$ at room temperature. Finally, $100 \mu \mathrm{l}$ stop solution was added. The A value of each well (detection wavelength, $450 \mathrm{~nm}$; reference wavelength, $690 \mathrm{~nm}$ ) and the magnitude of the A value represented the level of telomerase activity.

HDE extraction. A total of $200 \mathrm{~g}$ Oldenlandia diffusa Willd was weighed. Subsequently, the plant was incubated with $5.4180 \%$ ethanol for $30 \mathrm{~min}$ at room temperature, followed by reflux-extraction for $110 \mathrm{~min}$ at $80^{\circ} \mathrm{C}$. Following filtering, the filtrate was dried at $45^{\circ} \mathrm{C}$ to obtain Hedyotis diffusa. The extracts were suspended in $200 \mathrm{ml}$ distilled water and separately re-extracted four times with an equal volume of petroleum ether, ethyl acetate or n-butanol. Subsequently, the extracts were combined. The extracts of Hedyotis diffusa were named HDP (petroleum ether extract), HDE (ethyl acetate extract), HDB (n-butanol extract) and HDW (water fraction). HDE (5 g) was suspended in $100 \mathrm{ml}$ distilled water and HPD-300 macroporous resin was used for dynamic adsorption at an adsorption flow rate of $0.5 \mathrm{ml} / \mathrm{min}$ (diameter:height $=1: 10$ ), and then eluted with water until the residue was colorless. Dynamic elution was performed with $60 \%$ ethanol at a flow rate of $1 \mathrm{ml} / \mathrm{min}$. Finally, the eluate was collected and dried under reduced pressure.

Chemical analysis of HDE. The ultra-performance liquid chromatography-tandem mass spectrometry (UPLC-MS/MS) system (Waters Corporation) was used to determine the chemical constituents of HDE. The filtered sample (per $20 \mu \mathrm{l}$ ) was separated using an Inertsil C18 column $(250 \times 4.6 \mathrm{~mm} ; 5 \mu \mathrm{m}$; Agilent Technologies Inc.) at $30^{\circ} \mathrm{C}$, with a controlled flow rate of $1 \mathrm{ml} / \mathrm{min}$ at a set wavelength of $310 \mathrm{~nm}$. The mobile phase was composed of (A) acetonitrile and (B) $0.05 \%$ methanoic acid and used for gradient elution of HDE at $0 \mathrm{~min}(85: 15 \mathrm{v} / \mathrm{v})$, $15-20 \mathrm{~min}(80: 20 \mathrm{v} / \mathrm{v})$ and 30-60 $\mathrm{min}(75: 15 \mathrm{v} / \mathrm{v})$. For mass spectrometry, ultra-high-purity argon (Ar) and high-purity nitrogen (N2) were used as the collision gas and the nebulizing gas, respectively. Ultra-high-purity argon (Ar) and high-purity nitrogen (N2) were used as the collision gas and the nebulizing gas, respectively. The ESI(-) source was operated under the following conditions: $2.0 \mathrm{kV}$ source voltage, 38psi nebulizer pressure, $350^{\circ} \mathrm{C}$ nitrogen gas temperature, with a controlled 
flow rate of $1 \mathrm{ml} / \mathrm{min}, 100^{\circ} \mathrm{C}$ source temperature, $300^{\circ} \mathrm{C}$ capillary temperature, $500 \mathrm{l} / \mathrm{h}$ gas flow rate and full scanning mode. The CA ion $(163 \mathrm{~m} / \mathrm{z})$ produced three primary fragments in MS/MS (119, 93 and $65 \mathrm{~m} / \mathrm{z})$ and the E-CSME ion $(549 \mathrm{~m} / \mathrm{z})$ also produced three primary fragments in MS/MS (163, 119 and $89 \mathrm{~m} / \mathrm{z}$ ). Each chromatographic peak was identified by comparing the mass spectrum with the NIST mass spectral database (http://www.nist.gov/nist). For further verification, the retention time and mass data of each peak were compared with the reference standard compound. All chromatograms and mass spectra were analyzed using the Micromass MassLynx data system (MassLynx 4.1; Waters Corporation).

The total coumarin content of HDE was determined by spectrophotometry using a UV-vis spectrophotometer (Shimadzu Corporation) based on the method described by Wang et al (30). Briefly, $1.0 \mathrm{~g}$ dried HDE was dissolved in $100 \mathrm{ml} 70 \%$ ethanol and soaked in the dark for $24 \mathrm{~h}$ at room temperature. After filtration, the absorbance of HDE solution at a wavelength of $310 \mathrm{~nm}$ was determined. The total coumarins were calculated using a standard curve prepared with reference standard p-coumaric acid (CA; Selleck Chemicals) and expressed in terms of $\mathrm{mg}$ of $\mathrm{CA}$ equivalents per $\mathrm{g}$ of dried HDE.

Flow cytometry analysis. SKM-1 cells $\left(8 \times 10^{4}\right.$ cells/well) in the logarithmic growth phase were seeded into 6-well plates. Cell apoptosis was assessed using the Apoptosis detection kit (Biouniquer Technology Co., Ltd.). Following drug treatment/transfection for $24 \mathrm{~h}$, BMSCs and SKM-1 cells were washed twice with pre-cooled PBS. Subsequently, $300 \mu 1$ binding buffer was added to each well. Annexin V-FITC (5 $\mu \mathrm{l})$ was added to each well, gently mixed and incubated in the dark for $15 \mathrm{~min}$ at room temperature. Subsequently, propidium iodide $(10 \mu \mathrm{l})$ was added to each well, gently mixed and incubated for $10 \mathrm{~min}$ at room temperature in the dark. Stained cells were analyzed using a FACSCalibur (BD Biosciences) and CellQuest software (version 1.2; BD Biosciences).

Western blotting. Following treatment for $24 \mathrm{~h}$, SKM-1 cells and untreated BMSCs were harvested and total protein was extracted using 2X SDS lysis buffer (Cell Signaling Technology, Inc.). Total protein was quantified using the bicinchoninic acid assay (Sangon Biotech Co., Ltd.). A total of $20 \mu \mathrm{l}$ protein samples was separated via $12 \%$ SDS-PAGE and transferred onto PVDF membranes. The membranes were blocked with 5\% skimmed milk in TBST for $2 \mathrm{~h}$ at room temperature. Subsequently, the membranes were incubated with primary antibodies $(1: 1,000)$ overnight at $4^{\circ} \mathrm{C}$. The primary antibodies included hTERT (cat. no. ab32020; Abcam), caspase-3 (cat. no. ab184787; Abcam), caspase- 8 (cat. no. ab108333; Abcam), PARP (cat. no. ab139417; Abcam) and $\beta$-actin (cat. no. ab124964; Abcam). Following primary incubation, the membranes were incubated with a horseradish peroxidase-conjugated secondary antibody (1:5,000, Bio-Rad Laboratories, Inc.) at room temperature for $2 \mathrm{~h}$. All antibodies were purchased from Cell Signaling Technology, Inc. $\beta$-actin was used as a loading control. Protein bands were visualized using Western blotting Luminol reagent (Biological Industries).
Statistical analysis. Statistical analyses were conducted using SPSS software (version 17.0; SPSS, Inc.). Comparisons between two groups were analyzed using unpaired Student's t-tests. Comparisons among multiple groups were analyzed using one-way ANOVAs followed by the Dunnett's and Tukey's post hoc test with GraphPad Prism software (version 5.0; GraphPad Software, Inc.). $\mathrm{P}<0.05$ was considered to indicate a statistically significant difference. Experiments were performed in triplicates.

\section{Results}

Chemical analysis of HDE. The UPLC-MS/MS method displayed high precision and sensitivity, with mass accuracy of $<10$ ppm (data not shown). The chromatogram (Fig. 1) displayed two distinct chromatographic peaks with good resolution and response in negative ion mode. Peak 1 and peak 2 were identified as CA and E-6-O-p-coumaroyl scandoside methyl ester (E-CSME), respectively, based on their MS and MS/MS spectra, as well as UV retention time, compared with the reference standard compounds. The CA ion $(163 \mathrm{~m} / \mathrm{z})$ produced three primary fragments in MS/MS (119, 93 and $65 \mathrm{~m} / \mathrm{z})$, and the E-CSME ion $(549 \mathrm{~m} / \mathrm{z})$ also produced three primary fragments in MS/MS (163, 119 and $89 \mathrm{~m} / \mathrm{z})$. The results indicated that the total coumarin content of HDE was $87.4 \%$.

HDE combined with BIIB021 significantly inhibits SKM-1 cell proliferation and telomerase activity. To determine the anti-MDS efficacy of extracted HDE and BIIB021, the inhibitory effects of the two drugs on SKM-1 cell proliferation were assessed by performing the CCK- 8 assay. The concentration ranged from 0 to $200 \mu \mathrm{g} / \mathrm{ml}$ for $\mathrm{HDE}$ and 0 to $400 \mathrm{nmol} / 1$ for BIIB021. SKM-1 cell proliferation gradually decreased with increasing HDE and BIIB021 concentrations (Fig. 2A and B). The $\mathrm{IC}_{50}$ of HDE was $98.03 \mu \mathrm{g} / \mathrm{ml}$ and the $\mathrm{IC}_{50}$ of BIIB021 was $171.7 \mathrm{nmol} / 1$ in SKM-1 cells, which were used for subsequent experiments.

Compared with the control group, HDE or BIIB021 treatment inhibited cell proliferation $(\mathrm{P}<0.01)$, whereas the inhibitory effect of the two drugs on cell proliferation was significantly increased in the HDE+BIIB021 combination group (Fig. 2C; $\mathrm{P}<0.01$ ). To explore the mechanism underlying the inhibitory effects of HDE and BIIB021 on SKM-1 cell proliferation, the telomerase activity in BMSCs and SKM-1 cells was assessed. The results indicated that telomerase was highly activated in SKM-1 cells compared with BMSC (Fig. 2D; P<0.01), but significantly inhibited by HDE, BIIB021 or combination treatment (Fig. 2D; $\mathrm{P}<0.01$ ).

HSP90 expression. The expression of HSP90 in each group was assessed via RT-qPCR. HSP90 was highly expressed in SKM-1 cells compared with BMSC $(\mathrm{P}=0.00016)$. HDE $(\mathrm{P}=0.0012)$, BIIB021 $(\mathrm{P}=0.0009)$ or combination $(\mathrm{P}=0.0005)$ treatment significantly reduced HSP90 expression levels in SKM-1 cells compared with untreated SKM-1 cells (Fig. 2E).

Decreased expression of hTERT and treatment with $H D E+B I I B 021$ enhances the inhibitory effect and induces SKM-1 cellapoptosis.siRNAsweresynthesized toinhibithTERT expression. The transfection efficiency of hTERT-siRNAs was 


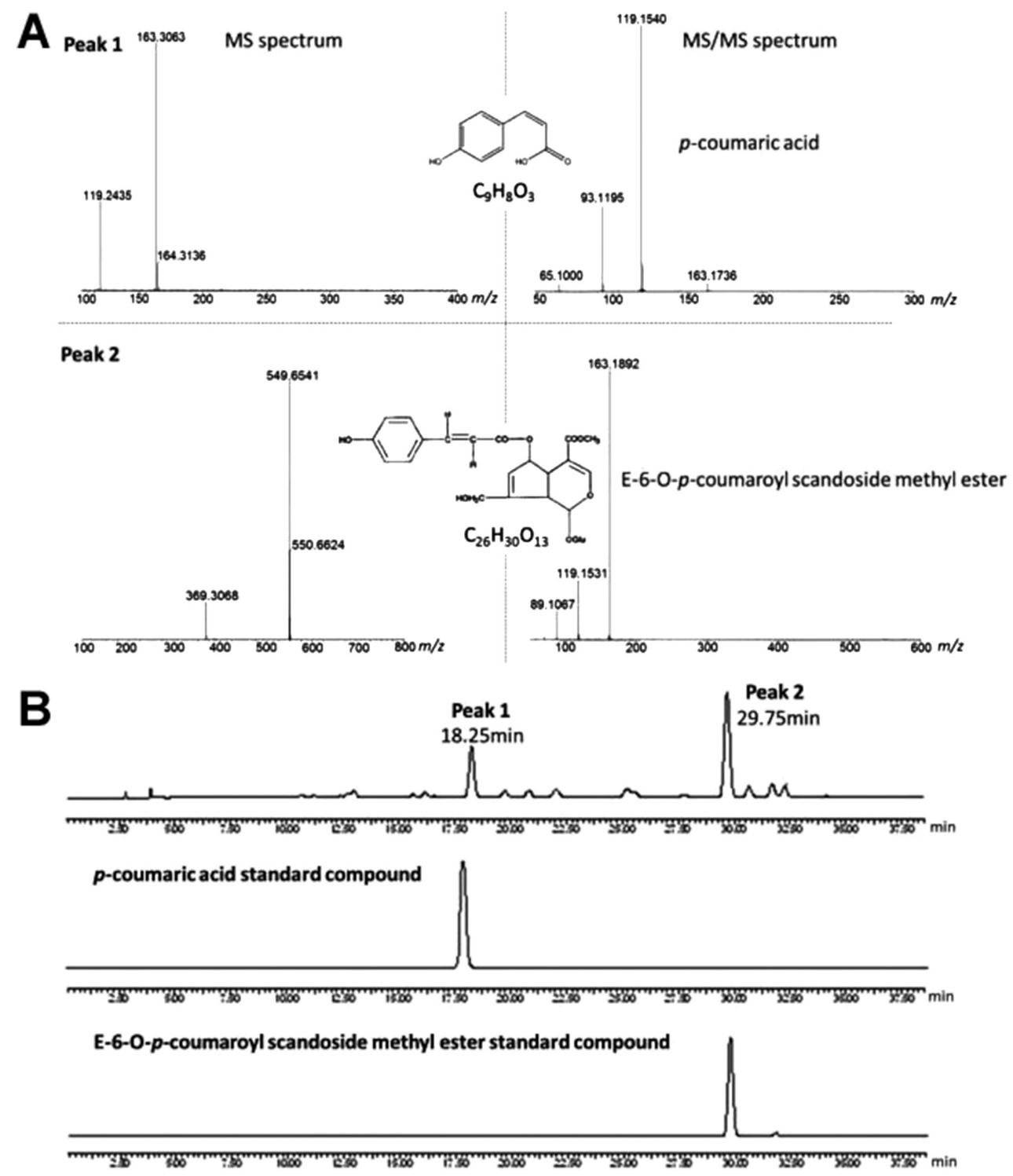

Figure 1. Chemical analysis of HDE. (A) Mass spectrums and (B) chromatograms of HDE and reference standard compounds. MS, mass spectrometry.

assessed, which indicated that hTERT-siRNA-966 significantly decreased hTERT expression compared with the control group (Fig. 3); therefore, hTERT-siRNA-966 was used for subsequent experiments. Subsequently, hTERT-siRNA-transfected SKM-1 cells were treated with HDE, BIIB021 or combination treatment, and cell apoptosis was assessed via flow cytometry (Fig. 4A). The results indicated that HDE or BIIB021 treatment significantly induced SKM-1 cell apoptosis compared with non-treated SKM-1 cells (Fig. 4B; P<0.01). hTERT knockdown combined with HDE or BIIB021 treatment significantly increased SKM-1 cell apoptosis compared with SKM-1 cells treated with HDE and hTERT knockdown combined with BIIB021 treatment also remarkably increased cell apoptosis when compared with SKM-1 cells treated with BIIB021 (Fig. 4B; $\mathrm{P}<0.01$ ). Moreover, HDE+BIIB021 combination treatment-induced SKM-1 cell apoptosis was enhanced by hTERT knockdown (Fig. 4B; P<0.01).

hTERT knockdown-induced SKM-1 cell apoptosis is enhanced by treatment with single drug or combination of two drugs. To investigate the mechanism underlying HDE in promoting cancer cell apoptosis, treated BMSCs and SKM-1 cells were homogenized to measure the protein expression levels of hTERT, caspase 3 , cleaved caspase 3 , caspase 8 , cleaved caspase 8 , PARP and cleaved PARP by western blotting (Fig. 5). Compared with BMSCs, protein expression in SKM-1 cells was not notably altered. However, the expression levels of hTERT, cleaved caspase 3, cleaved caspase 8 and cleaved PARP were increased following HDE, BIIB021 or HDE+BIIB021 treatment compared with non-treated SKM-1 cells. Additionally, following hTERT knockdown, the expression levels of cleaved caspase 3 , cleaved caspase 8 and cleaved PARP were slightly increased compared with the hTERT-siNC group. By contrast, there was no notable difference in protein expression levels among the BMSC, SKM-1 and hTERT-siNC groups. Furthermore, following HDE, BIIB021 or HDE+BIIB021 treatment, the expression levels of cleaved caspase 3 , cleaved caspase 8 and cleaved PARP were increased in hTERT knockdown SKM-1 cells compared with hTERT-siNC-transfected SKM-1 cells. The results further 

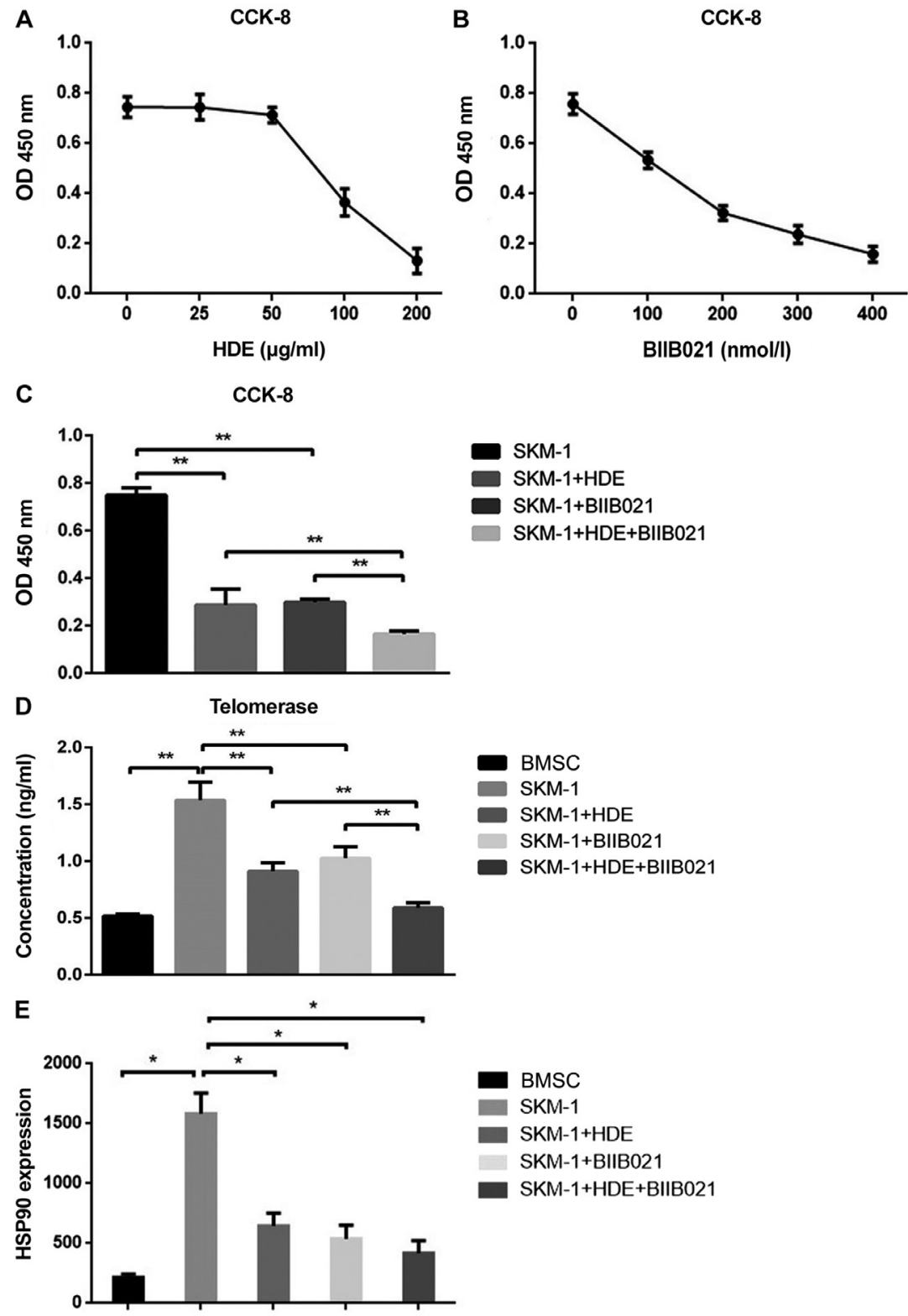

Figure 2. Effect of drug treatment on cell proliferation and telomerase activity in SKM-1 cells. (A) Effects of different concentrations of HDE on cell proliferation. The $\mathrm{IC}_{50}$ of HDE was $98.03 \mu \mathrm{g} / \mathrm{ml}$. (B) Effects of different concentrations of BIIB021 on cell proliferation. The IC ${ }_{50}$ of BIIB021 was $171.7 \mathrm{nmol} / 1$. (C) Effects of HDE and BIIB021 on cell proliferation (SKM-1+HDE vs. SKM-1, P=0.004; SKM-1+BIIB021 vs. SKM-1, P=0.001; SKM-1+HDE+BIIB021 vs. SKM-1, $\mathrm{P}=0.001$ ). (D) Effects of HDE and BIIB021 on telomerase activity in BMSCs and SKM-1 cells (BMSC vs. SKM-1, P=0.0004; SKM-1+HDE vs. SKM-1, $\mathrm{P}=0.0036 ; \mathrm{SKM}-1+\mathrm{BIIB} 021$ vs. SKM-1, $\mathrm{P}=0.0094$; SKM-1+HDE+BIIB021 vs. SKM-1, P=0.0006; SKM-1+HDE vs. SKM-1+HDE+BIIB021, P=0.0031; SKM-1+BIIB021 vs. SKM-1+HDE+BIIB021, P=0.0022). (E) HSP90 expression levels in BMSCs and SKM-1 cells (BMSC vs. SKM-1, P=0.00016; SKM-1 vs. SKM-1+HDE, P=0.0012; SKM-1 vs. SKM-1+BIIB021, P=0.0009; SKM-1 vs. SKM-1+HDE+BIIB021, P=0.0005). hUC-MSC, human umbilical cord-mesenchymal stem cells; BMSC, bone marrow-derived stem cell; OD, optical density. ${ }^{*} \mathrm{P}<0.05,{ }^{* *} \mathrm{P}<0.01$.

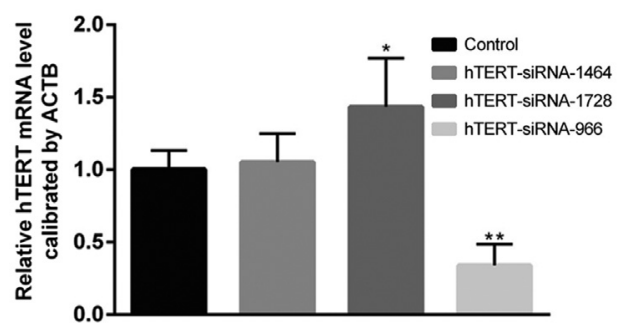

Figure 3. Transfection efficiency of hTERT siRNA. Among the three siRNAs, hTERT-siRNA 966 displayed the highest efficiency in downregulating hTERT expression compared with the control group (hTERT-siRNA-1464 vs. control, P=0.73; hTERT-siRNA-1728 vs. control, $\mathrm{P}=0.73$; hTERT-siRNA-966 vs. Control, $\mathrm{P}=0.0041$ ). hTERT, human telomerase reverse transcriptase; siRNA, small interfering RNA; ACTB, actin $-\beta .{ }^{*} \mathrm{P}<0.05,{ }^{* * *} \mathrm{P}<0.01$. indicated that hTERT knockdown facilitated the antitumor effects of HDE and BIIB021.

\section{Discussion}

Ineffective hematopoiesis with peripheral cytopenia despite normo or hypercellular bone marrow is the hallmark of MDSs, especially in the low-risk subgroups. It is caused by increased secretion of inhibitory cytokines in the marrow; however, the underlying mechanisms are not completely understood (31). Immunoinhibitory or modulatory therapy aims to restore hematopoiesis by reversing inhibitory processes, and includes anti-thymocyte globulin (ATG), cyclosporin A (CSA), 

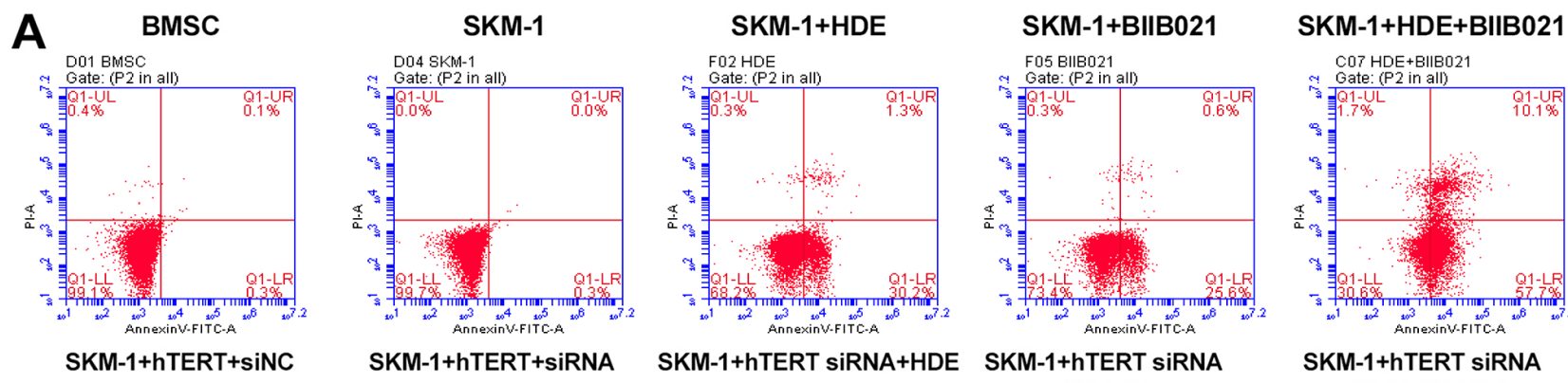

SKM-1+hTERT+siNC
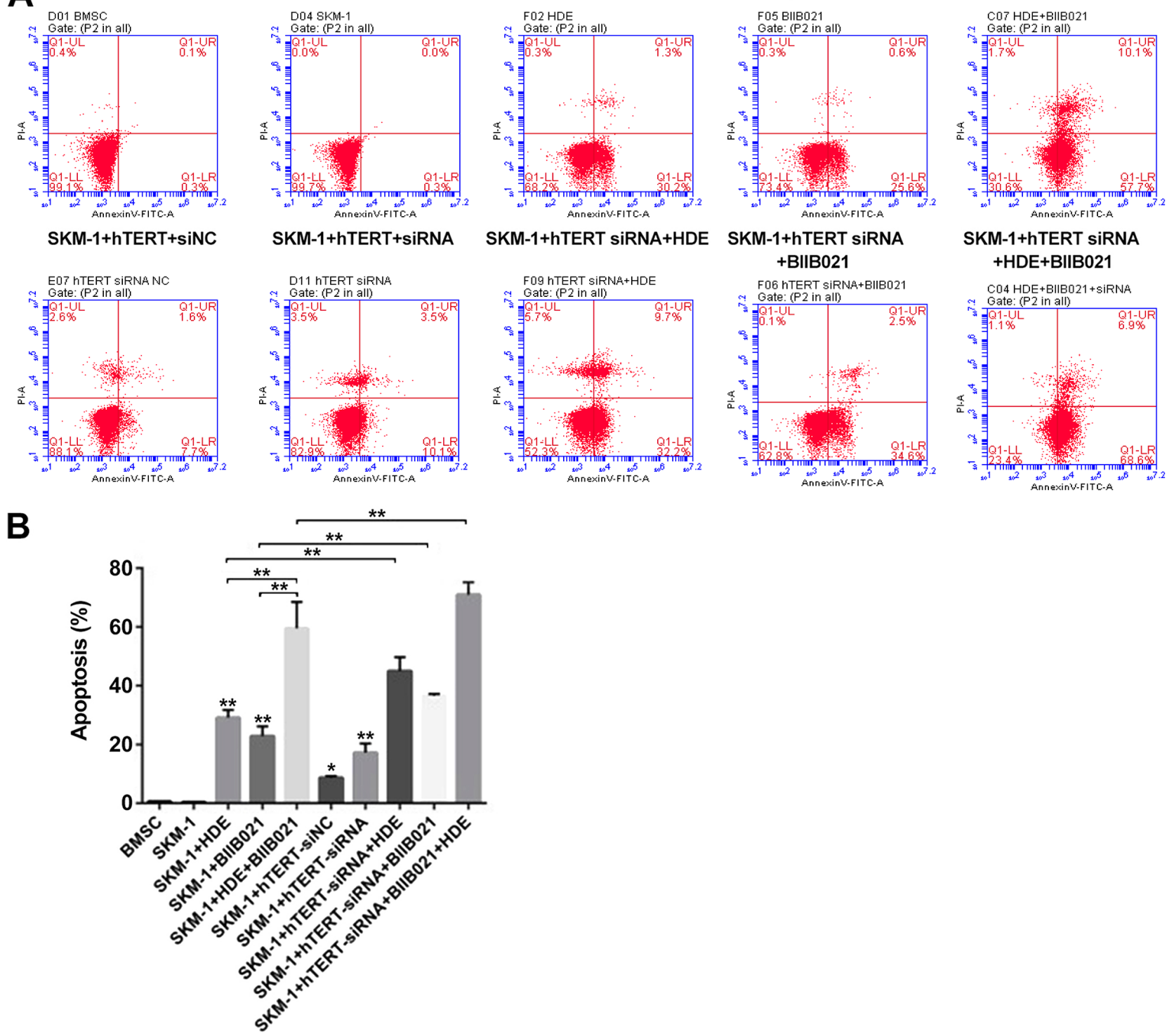

Figure 4. hTERT knockdown induces SKM-1 cell apoptosis after treatment with HDE+BIIB021. SKM-1 cell apoptosis was (A) determined via flow cytometry and (B) quantified (SKM-1+HDE vs. SKM-1, P=0.0001; SKM-1+BIIB021 vs. SKM-1, P=0.0003; SKM-1+HDE+BIIB021 vs. SKM-1, P=0.003; SKM-1+hTERT-siNC vs. SKM-1, P=0.0001; SKM-1+hTERT-siRNA vs. SKM-1, P=0.0007; SKM-1+hTERT-siRNA+HDE vs. SKM-1, P=0.0001; SKM-1+hT ERT-siRNA+BIIB021 vs. SKM-1, P=0.0001; SKM-1+hTERT-siRNA+BIIB021+HDE vs. SKM-1, P=0.0007). hTERT, human telomerase reverse transcriptase; si, small interfering RNA; NC, negative control. ${ }^{*} \mathrm{P}<0.05,{ }^{* *} \mathrm{P}<0.01$.

direct TNF-inhibitors and lenalidomide (32). A simple scoring system, using age, duration of transfusion dependency and HLA-DR15 status, has been developed, which facilitates identification of patients with a high, intermediate or low probability of response to treatment with ATG (33). Other immunosuppressive agents that can also induce responses, such as CSA, have been combined with ATG, but have not yet been fully evaluated for their potential role in the treatment of MDS (32). Lenalidomide displays superior efficacy in the 5q-syndrome, but low efficacy in other patients with low-risk MDS (34). Additional clinical trials are required to define the potential of immunosuppressive and modulatory treatment in MDS $(35,36)$. Thus, identifying safer and more effective anti-MDS strategies remains a major global health challenge. In our previous study, TCHD displayed proapoptotic effects in SKM-1 cells, and the underlying mechanism was associated with the inhibition of the PI3K/Akt signaling pathway and activation of caspase proteins (23). A further two new compounds, CA and E-CSME, were identified in TCHD (23). Also, the newly extracted compound of HDE efficiently inhibited leukemia cell proliferation and induced cancer cell apoptosis with our patented extraction technology (patent no. ZL201410324070.2).

Patients with higher-risk MDS with AML transformation display higher hTERT mRNA expression levels compared with healthy individuals and patients with low-risk MDS (37). hTERT-positive patients can easily develop leukemia (37), indicating that hTERT is positively related to the progression of MDS. Several natural drugs can inhibit the function of HSP90, such as benzoquinone ansamycin antibiotics, radicicol and neomycin, by competing with ATP for binding to the $\mathrm{N}$-terminal conserved domain of HSP90 or interfering with 

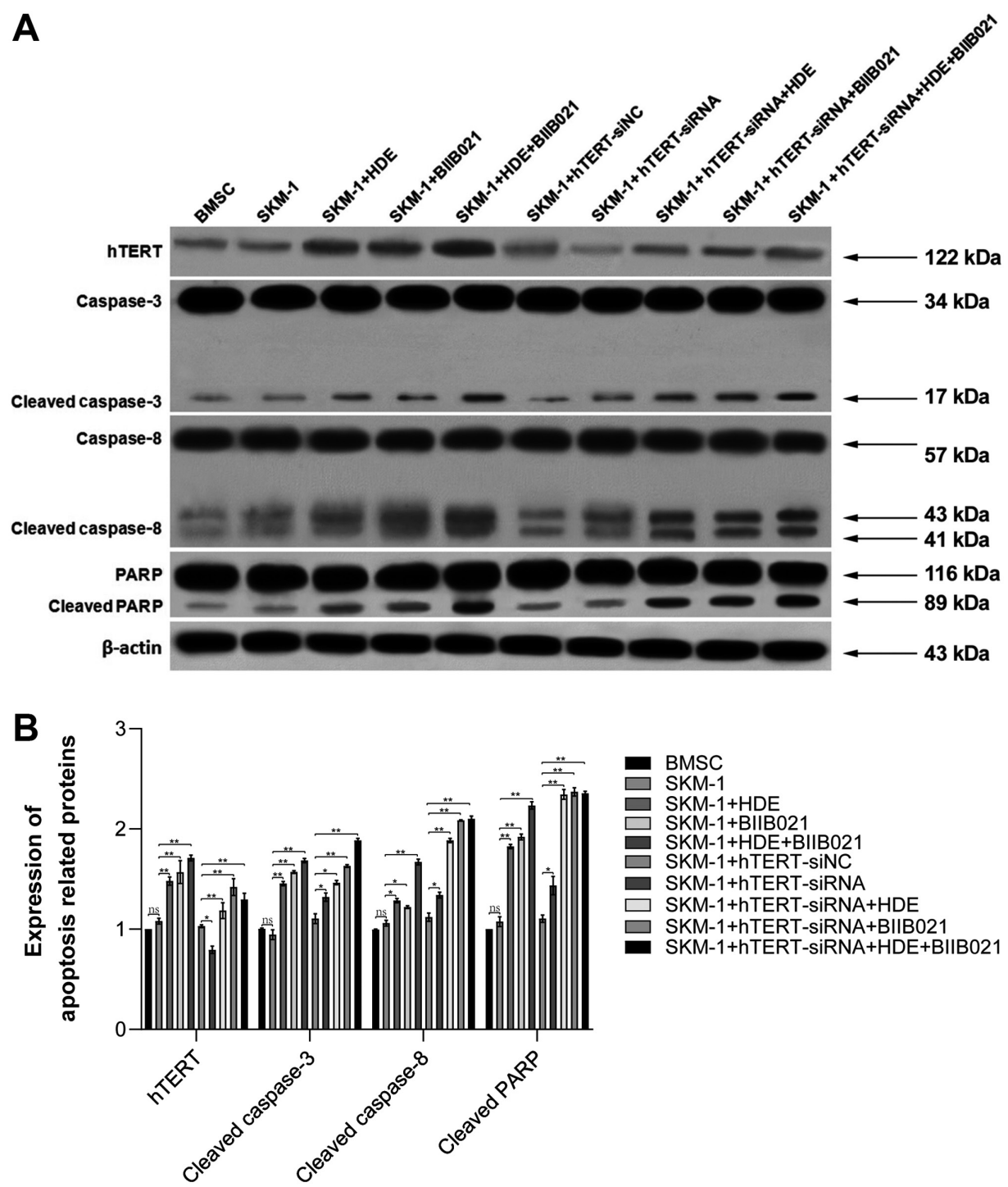

Figure 5. Effects of HDE and BIIB021 on apoptosis-related protein expression levels in SKM-1 cells. (A) Apoptosis-related protein expression levels in SKM-1 cells were analyzed by western blot analysis. (B) Apoptosis-related protein expression levels were semi-quantified using gray scanning. BMSC, bone marrow-derived stem cell; hTERT, human telomerase reverse transcriptase; si, small interfering RNA; NC, negative control; PARP, peroxisome proliferator-activated receptor. ${ }^{*} \mathrm{P}<0.05,{ }^{* *} \mathrm{P}<0.01$.

the interaction between HSP90 and other accessory chaperone proteins, thus reducing the stability of chaperone protein (38).

Previously, the synergistic effect of traditional Chinese medicine extract and chemotherapy drugs has been reported (39). Similarly, a previous study has also demonstrated that both HDE and BIIB021 downregulated telomerase activity, and combined treatment further enhanced the tumor apoptosis-inducing effects of the compounds (40). BIIB021 outperforms other drugs as it displays independent anticancer effects with expression of multidrug resistance (MDR) proteins, such as P-gp and/or MDR-related protein 1, which typically confer resistance to a broad range of chemotherapeutic agents and molecularly targeted drugs (41-44). The prolonged inhibitory effects of BIIB021 on proliferation could increase its clinical applicability. In vitro experiments indicated that BIIB021 can competitively bind to the N-terminal ATP/ADP domain of HSP90, downregulate the expression of chaperones HER2, Akt, and Raf-1, and upregulate HSP70 and HSP27, with a broad spectrum of antitumor activities $(20,45)$.
HDE may share a similar anticancer mechanism with BIIB021, but further investigation is required. In addition, HDE is extracted from the natural herb Hedyotis diffusa, which has been used for cancer treatment in China for centuries (46). Previous studies have demonstrated that TCHD could induce apoptosis in leukemia cell lines Kasumi-1, KG-1, THP-1, U937 and K562 $(47,48)$. The present study in SKM-1 cells further demonstrated the broad-spectrum antileukemia benefits of TCHD. In the future, a preclinical study should be conducted to identify other purified coumarin components with fewer side effects and improved efficacy.

The present study indicated that downregulation of hTERT by siRNA might serve as a more direct strategy to inhibit cancer cell proliferation. Following hTERT knockdown, the flow cytometry results suggested that the apoptotic rate was increased in HDE- or BIIB021-treated SKM-1 cells. Antitumor effects were observed with a combination of the two drugs following hTERT knockdown. The western blotting results further indicated that cleaved caspase 3 , cleaved 
caspase 8 and downstream target cleaved PARP, which are involved in apoptosis pathways, were upregulated following hTERT knockdown compared with the hTERT-siNC group. Collectively, the results indicated an additive effect between the two drugs. However, the lack of cell proliferation analysis with trypan blue was a key limitation of the present study. Therefore, further mechanisms underlying HDE require investigation in future studies.

In conclusion, the present study identified a new active component HDE in Oldenlandia diffusa Willd, which displayed apoptosis-inducing effects on the MDS-derived leukemia cell line SKM-1, and the underlying mechanism, which involved downregulation of hTERT expression. The present study indicated that HDE, due to its potent anti-MDS activity, may be valuable for the development of new therapies for patients with MDS.

\section{Acknowledgements}

Not applicable.

\section{Funding}

The present study was supported by the Great Item of Science and Technology Planning Project of Zhejiang Province (grant no. 2019C03047), the Medical and Health Science and Technology Plan of Zhejiang Province of China (grant no. 2017RC022) and the Traditional Chinese Medicine Science and Technology Plan Projects of Zhejiang Province (grant no. 2017ZQ012).

\section{Availability of data and materials}

The datasets used and/or analyzed during the current study are available from the corresponding author on reasonable request.

\section{Authors' contributions}

SL, YunZ and BW supervised the project. BW, JJ and YS designed the study. YunZ, JJ, ST, SL, YS and LW performed the experiments. BW, ST and SL wrote the manuscript. All authors read and approved the final manuscript.

\section{Ethics approval and consent to participate}

Not applicable.

\section{Patient consent for publication}

Not applicable.

\section{Competing interests}

The authors declare that they have no competing interests.

\section{References}

1. Adès L, Itzykson R and Fenaux P: Myelodysplastic syndromes. Lancet 383: 2239-2252, 2014.

2. Mitani K: Molecular pathogenesis of MDS. Rinsho Ketsueki 50: 1325-1331, 2009 (In Japanese).
3. Malcovati L, Hellström-Lindberg E, Bowen D, Adès L, Cermak J, Del Cañizo C, Della Porta MG, Fenaux P, Gattermann N, Germing U, et al; European Leukemia Net: Diagnosis and treatment of primary myelodysplastic syndromes in adults: Recommendations from the European LeukemiaNet. Blood 122: 2943-2964, 2013.

4. Cheson BD, Greenberg PL, Bennett JM, et al: Clinical application and proposal for modification of the International Working Group (IWG) response criteria in myelodysplasia. Blood 108: 419-425, 2006.

5. Cogle CR, Craig BM, Rollison DE and List AF; CR C: Incidence of the myelodysplastic syndromes using a novel claims-based algorithm: High number of uncaptured cases by cancer registries. Blood 117: 7121-7125, 2011

6. Greenberg PL, Tuechler H, Schanz J, Sanz G, Garcia-Manero G Solé F, Bennett JM, Bowen D, Fenaux P, Dreyfus F, et al: Revised international prognostic scoring system for myelodysplastic syndromes. Blood 120: 2454-2465, 2012.

7. Killick SB, Carter C, Culligan D, Dalley C, Das-Gupta E, Drummond M, Enright H, Jones GL, Kell J, Mills J, et al: British Committee for Standards in Haematology: Guidelines for the diagnosis and management of adult myelodysplastic syndromes. Br J Haematol 164: 503-525, 2014.

8. Greenberg PL, Stone RM, Al-Kali A, et al: Myelodysplastic Syndromes, Version 2.2017, NCCN Clinical Practice Guidelines in Oncology. J Natl Compr Canc Netw 15: 60-87, 2017.

9. Macedo LC, Silvestre AP, Rodrigues C, de Alencar JB, Zacarias JM, Ambrosio-Albuquerque EP, Sell AM and Visentainer JE: Genetics factors associated with myelodysplastic syndromes. Blood Cells Mol Dis 55: 76-81, 2015.

10. Grisendi S, Bernardi R, Rossi M, Cheng K, Khandker L, Manova K and Pandolfi PP: Role of nucleophosmin in embryonic development and tumorigenesis. Nature 437: $147-153,2005$

11. Schneider F, Hoster E, Unterhalt M, Schneider S, Dufour A, Benthaus T, Mellert G, Zellmeier E, Bohlander SK, Feuring-Buske M, et al: NPM1 but not FLT3-ITD mutations predict early blast cell clearance and CR rate in patients with normal karyotype AML (NK-AML) or high-risk myelodysplastic syndrome (MDS). Blood 113: 5250-5253, 2009.

12. Wimmer K, Vinatzer U, Zwirn P, Fonatsch C and Wieser R Comparative expression analysis of the antagonistic transcription factors EVI1 and MDS1-EVI1 in murine tissues and during in vitro hematopoietic differentiation. Biochem Biophys Res Commun 252: 691-696, 1998.

13. Graubert $\mathrm{T}$ and Walter MJ: Genetics of myelodysplastic syndromes: New insights. Hematology (Am Soc Hematol Educ Program) 2011: 543-549, 2011.

14. Bagatell R and Whitesell L: Altered Hsp90 function in cancer: A unique therapeutic opportunity. Mol Cancer Ther 3: 1021-1030, 2004.

15. Kamal A, Thao L, Sensintaffar J, Zhang L, Boehm MF, Fritz LC and Burrows FJ: A high-affinity conformation of Hsp90 confers tumour selectivity on Hsp90 inhibitors. Nature 425: 407-410, 2003.

16. Flandrin P, Guyotat D, Duval A, Cornillon J, Tavernier E, Nadal $\mathrm{N}$ and Campos L: Significance of heat-shock protein (HSP) 90 expression in acute myeloid leukemia cells. Cell Stress Chaperones 13: 357-364, 2008.

17. Forsythe HL, Jarvis JL, Turner JW, Elmore LW and Holt SE: Stable association of hsp90 and p23, but Not hsp70, with active human telomerase. J Biol Chem 276: 15571-15574, 2001.

18. Pinkerton DM, Chow S, Eisa NH, Kainth K, Vanden Berg TJ, Burns JM, Guddat LW, Savage GP, Chadli A and Williams CM: Synthesis of the seco-Limonoid BCD Ring System Identifies a Hsp90 Chaperon Machinery (p23) Inhibitor. Chemistry 25: 1451-1455, 2019.

19. Duval A, Olaru D, Campos L, Flandrin P, Nadal N and Guyotat D: Expression and prognostic significance of heat-shock proteins in myelodysplastic syndromes. Haematologica 91: 713-714, 2006.

20. Flandrin-Gresta P, Solly F, Aanei CM, Cornillon J, Tavernier E, Nadal N, Morteux F, Guyotat D, Wattel E and Campos L: Heat Shock Protein 90 is overexpressed in high-risk myelodysplastic syndromes and associated with higher expression and activation of Focal Adhesion Kinase. Oncotarget 3: 1158-1168, 2012.

21. Chiosis G, Timaul MN, Lucas B, Munster PN, Zheng FF, Sepp-Lorenzino L and Rosen N: A small molecule designed to bind to the adenine nucleotide pocket of Hsp90 causes Her2 degradation and the growth arrest and differentiation of breast cancer cells. Chem Biol 8: 289-299, 2001. 
22. Lundgren K, Zhang H, Brekken J, Huser N, Powell RE, Timple N, Busch DJ, Neely L, Sensintaffar JL, Yang YC, et al: BIIB021, an orally available, fully synthetic small-molecule inhibitor of the heat shock protein Hsp90. Mol Cancer Ther 8: 921-929, 2009.

23. Jiang J, Wang B, Li J, Ye B, Lin S, Qian W, Shan L and Efferth T: Total coumarins of Hedyotis diffusa induces apoptosis of myelodysplastic syndrome SKM-1 cells by activation of caspases and inhibition of PI3K/Akt pathway proteins. J Ethnopharmacol 196: 253-260, 2017.

24. Qin T, Castoro R, El Ahdab S, Jelinek J, Wang X, Si J, Shu J, He R, Zhang N, Chung W, et al: Mechanisms of resistance to decitabine in the myelodysplastic syndrome. PLoS One 6: e23372, 2011.

25. Di H, Liu D, Gao X, Xu Y, Wang Y and Wang Z: [TCM Diagnosis and Treatment Status of Myelodysplastic Syndrome]. World Chinese Medicine 9: 1557-1560, 2014.

26. Lee HZ, Bau DT, Kuo CL, Tsai RY, Chen YC and Chang YH: Clarification of the phenotypic characteristics and anti-tumo activity of Hedyotis diffusa. Am J Chin Med 39: 201-213, 2011.

27. Meng QX, Roubin RH and Hanrahan JR: Ethnopharmacological and bioactivity guided investigation of five TCM anticancer herbs. J Ethnopharmacol 148: 229-238, 2013.

28. Niu Y and Meng QX: Chemical and preclinical studies on Hedyotis diffusa with anticancer potential. J Asian Nat Prod Res 15: 550-565, 2013.

29. Livak KJ and Schmittgen TD: Analysis of relative gene expression data using real-time quantitative PCR and the 2(-Delta Delta C(T)) Method. Methods 25: 402-408, 2001.

30. Wang M, Jia M, Ma Y, Jiang G, Tang S and Xia L: Determination of coumarins content in Radix Angelicae dahuricae by HPLC and UV. Zhong Yao Cai 27: 826-828, 2004 (In Chinese).

31. Cazzola M: Myelodysplastic Syndromes. N Engl J Med 383 $1358-1374,2020$

32. Garg R, Faderl S, Garcia-Manero G, Cortes J, Koller C, Huang X, York S, Pierce S, Brandt M, Beran M, et al: Phase II study of rabbit anti-thymocyte globulin, cyclosporine and granulocyte colony-stimulating factor in patients with aplastic anemia and myelodysplastic syndrome. Leukemia 23: 1297-1302, 2009.

33. Saunthararajah Y, Nakamura R, Wesley R, Wang QJ and Barrett AJ: A simple method to predict response to immunosuppressive therapy in patients with myelodysplastic syndrome. Blood 102: 3025-3027, 2003.

34. Santini V: Treatment of low-risk myelodysplastic syndromes Hematology (Am Soc Hematol Educ Program) 2016: 462-469, 2016.

35. Gibbs JB: Mechanism-based target identification and drug discovery in cancer research. Science 287: 1969-1973, 2000.

36. Ganser A, Passweg J, Stadler M, Dobbelstein C and Weissinger EM: Immunosuppressive treatment strategies in low-risk MDS. Cancer Treat Rev 33: S11-S14, 2007.
37. Cogulu O, Kosova B, Gunduz C, Karaca E, Aksoylar S, Erbay A, Karapinar D, Vergin C, Vural F, Tombuloglu M, et al: The evaluation of hTERT mRNA expression in acute leukemia children and 2 years follow-up of 40 cases. Int J Hematol 87: 276-283, 2008.

38. Taldone T, Sun W and Chiosis G: Discovery and development of heat shock protein 90 inhibitors. Bioorg Med Chem 17: 2225-2235, 2009.

39. Wang B, Lin SY, Shen YY, Wu LQ, Chen ZZ, Li J, Chen Z, Qian WB and Jiang JP: Pure total flavonoids from Citrus paradisi Macfadyen act synergistically with arsenic trioxide in inducing apoptosis of Kasumi-1 leukemia cells in vitro. J Zhejiang Univ Sci B 16: 580-585, 2015.

40. Wang B, Zhang Y, Shen Y, Wu L, Zhou Y and Lin S [Downregulation of hTERT with Drug Combination of HDE and BIIB021 Efficiently Inhibit Cell Proliferation of and Induce Apoptosis in Myelodysplastic Syndromes]. 2019 Annual Meeting of the Hematology Specialty Committee of Zhejiang Integrative Medicine Association: 233, 2019.

41. Ambudkar SV, Kimchi-Sarfaty C, Sauna ZE and Gottesman MM: P-glycoprotein: From genomics to mechanism. Oncogene 22: 7468-7485, 2003.

42. Glavinas H, Krajcsi P, Cserepes J and Sarkadi B: The role of $\mathrm{ABC}$ transporters in drug resistance, metabolism and toxicity. Curr Drug Deliv 1: 27-42,2004.

43. Larsen AK, Escargueil AE and Skladanowski A: Resistance mechanisms associated with altered intracellular distribution of anticancer agents. Pharmacol Ther 85: 217-229, 2000.

44. Varma MV, Ashokraj Y, Dey CS and Panchagnula R: P-glycoprotein inhibitors and their screening: A perspective from bioavailability enhancement. Pharmacol Res 48: 347-359, 2003.

45. Zhang H, Neely L, Lundgren K, Yang YC, Lough R, Timple N and Burrows F: BIIB021, a synthetic Hsp90 inhibitor, has broad application against tumors with acquired multidrug resistance. Int J Cancer 126: 1226-1234, 2010

46. Fang T, Yan YX, Yang Y, Lv YX, Chang QQ and Zhang DD: Ethyl Acetate Fraction from Hedyotis diffusa plus Scutellaria barbata Suppresses Migration of Bone-Metastatic Breast Cancer Cells via OPN-FAK/ERK/NF- $\kappa$ B Axis. Evid Based Complement Alternat Med 2020: 3573240, 2020.

47. Chen Z, Wang B, Qiu M, Lin SY and Xiong H: [Proliferation Inhibition and Its Mechanism of Total Coumarins on Leukemia Cells]. Chinese Pharmaceutical Journal 52: 1503-1509, 2017.

48. Chen Z, Lin S, Jiang J, et al: [Inhibitory Effect of Total Coumarins of Hedyotis diffusa Willd on the Growth of AML Cell Line Kasumi-1]. Chinese Journal of Integrated Traditional and Western Medicine 37: 1089-1094, 2017. 